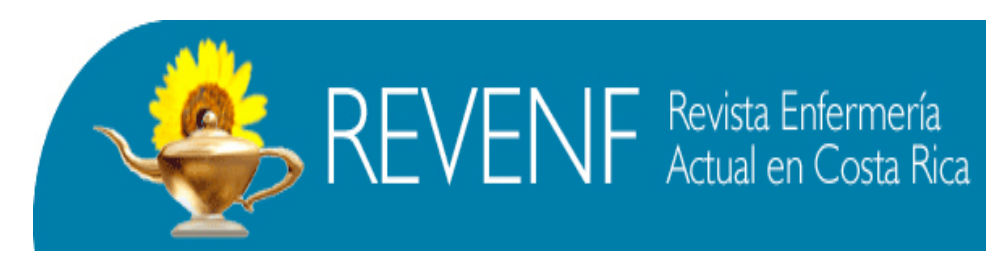

Revista Semestral Número 17 Octubre 2009 - Marzo 2010

ISSN 1409-4568

\title{
La Salud Internacional y el Consumo de Drogas por parte de la población adolescente de Costa Rica ${ }^{1}$
}

\section{COMO CITAR ESTE ARTÍCULO}

Vargas Vargas, Esteban y otros. La salud internacional y el consumo de drogas por parte de la población adolescente de Costa Rica. Rev. Enfermería Actual en Costa Rica [en línea].2009, No.17 [citado (fecha)]. Disponible World Wide Web: $<$ http://www.revenf.ucr.ac.cr/saludinternacional.pdf> ISSN 1409-4568

\begin{abstract}
Resumen
La Salud Internacional constituye una visión en la que la persona es concebida como un ser integral que se forma en un proceso dinámico en el que, según Wright (1999), intervienen factores macro y microdeterminantes. En el presente artículo se presentan los resultados de un estudio en el que se investigó la relación entre los microdeterminantes y el consumo de drogas por parte de la población adolescente. Por otra parte, la investigación fue realizada desde el mes de marzo, del año 2008 , hasta noviembre de ese mismo año.

La investigación tiene un enfoque cuantitativo, es de tipo no experimental y el diseño es transeccional descriptivo. La población del estudio está constituida por funcionarios y funcionarias de instituciones nacionales involucradas con el fenómeno de las drogas. La recolección de los datos se realizó por medio de una entrevista personal y fue reforzada con la revisión de otros textos lo cual permitió triangular la información. Entre los resultados se destaca la poca conexión interinstitucional para abordar el fenómeno de las drogas y la percepción multicausal del mismo pero con un abordaje local.

Se concluye cuán importante es que la Enfermería aplique el enfoque de Salud Internacional para abordar el fenómeno de las drogas en la adolescencia.
\end{abstract}

Esteban Vargas Vargas ${ }^{2}$

Vilma Barrio Sequerira ${ }^{3}$

Marta Campos Palacios ${ }^{4}$

Danny Porras Monge

Karla Quesada Quirós ${ }^{6}$

Viriam Leiva Díaz ${ }^{7}$

Palabras claves: drogas lícitas, drogas ilícitas, adolescentes, salud internacional, enfermería.

\footnotetext{
${ }^{1}$ Fecha de recepción: marzo 2009

Fecha de aceptación: Agosto 2009

${ }^{2}$ Licenciado en Enfermería, Servicio de Hospitalización del Instituto Nacional de Seguros. Tel. 88646791.

${ }^{3}$ Licenciada en Enfermería, Servicio de Hospitalización del Instituto Nacional de Seguros. Tel. 88295239.

${ }^{4}$ Licenciada en Enfermería, Hospital Clínica La Católica. Tel. 89951076.

${ }^{5}$ Licenciado en Enfermería, Hospital Clínica Santa María. Tel. 88762358.

${ }^{6}$ Licenciada en Enfermería, Clínica Clodomiro Picado Twight. Tel. 88963018.

${ }^{7}$ Enfermera, Magister en Psicopedagogía, Profesora Asociada Escuela de Enfermería, Universidad de Costa Rica. Correo electrónico: viriml@gmail.com
} 


\begin{abstract}
International Health is a vision that conceives the person as a whole, where a dynamic process is established in which, according to Wright (1999), elements known as macro and microdeterminants have influence. This article presents the results of those microdeterminants and its influence in the phenomenon of drugs in adolescents; the research was made from March to November 2008. The investigation had a quantitative focus, of a non- experimental type and a descriptive transactional design. The population consisted of employees of national institutions involved in this phenomenon. The recollection of data was made by a personal interview and reinforced with documental and literary review which allowed the information to be valid. Among the most important results are: the poor interinstitutional connection to deal with phenomenon of drugs and the knowledge of various causes to this problem but the dealing of only a few of them. In conclusion, it was seen that it is very important for Nursery to use the aspects involved in International Health to give a more wholesome treating to the phenomenon of drugs in adolescents.
\end{abstract}

Keywords: international health, licit drugs, illicit drugs, adolescents, nursing.

\section{Introducción.}

El fenómeno de las drogas es un problema mundial debido a las implicaciones sociales, monetarias y humanas, igualmente, representa una amenaza para la estabilidad de las instituciones sociales, políticas y jurídicas de los países. Al respecto, la Organización Panamericana de la Salud (1995) menciona que esta enfermedad se propaga rápidamente con el inconveniente de que los gobiernos no tienen los medios ni las medidas adecuadas para atacarlo eficazmente. Dado lo anterior, es necesario que el fenómeno de las drogas sea estudiado desde una perspectiva más amplia tal como la Salud Internacional la cual está integrada por componentes sociales, políticos, monetarios, familiares $\mathrm{y}$ personales y de relaciones internacionales y mundiales.

La población adolescente es uno de los grupos más afectados por esta problemática: en Costa Rica representa el
$26.6 \%$ de la población total, lo que equivale a 1,013.508 de personas (V Informe del Estado de los Derechos de la niñez y la adolescencia en Costa Rica, 2005). La vulnerabilidad de dicho sector se debe a la etapa del desarrollo en que se encuentra puesto que en ésta hay grandes cambios físicos, cognitivos, psicosociales y sexuales; si a lo anterior se agregan, de acuerdo con (Wright 2000), factores como la pobreza, la violencia social, la influencia de culturas foráneas, el desempleo, las relaciones familiares disfuncionales, la pérdida de valores y la escasa atención de salud, hace a la persona joven, es aún más fácil que los/as jóvenes se vean envueltos en esta problemática. Por tanto, como lo menciona Donas (1995), cuando se habla de la salud integral de la adolescencia debe tenerse una visión amplia que tome en cuenta las características específicas de cada estructura social y cultura de cada país. Lo mencionado concuerda con el enfoque de la Salud Internacional respecto del fenómeno de las drogas. 
Un aspecto que pone de manifiesto la problemática de las drogas en este grupo poblacional es la prevalencia de consumo de drogas tanto licitas como ilícitas. Según datos del Instituto sobre Farmacodependencia y Alcoholismo (IAFA), en el año 2000, el alcohol se colocó en primer lugar (48\%), el tabaco en el segundo $(31,1 \%)$ y en tercer lugar la marihuana (6,8\%). En cuanto a la edad de inicio de consumo, según el IAFA (2006) y la Organización Iberoamericana de la Juventud (OIJ, 1995), los jóvenes inician cada vez más temprano el consumo de drogas ya que antes iniciaban a los 15 años y, en la actualidad, a los 13 años de edad en promedio: esta edad coincide con la finalización de la educación primaria y el inicio de la secundaria.

El IAFA realizó una investigación, en el año 2006, con la cual concluyó que más de una cuarta parte de la población de estudiantes de secundaria -de Costa Ricaha experimentado con alguna droga ilícita; igualmente, la institución encontró dificultades para el diseño, interiorización e impacto de los cursos preventivos sobre el uso de drogas dirigidos a esta población. Tal hecho es preocupante debido a que son un medio fundamental para la prevención en el consumo de drogas, no obstante, su impacto, en el país, no es el que se pensaba.

En vista de esta problemática, y de la vulnerabilidad de la población adolescente para involucrarse en el uso y abuso de drogas, urge que las disciplinas en Salud, dentro de ellas la Enfermería, realicen investigaciones integrales acerca de los diferentes componentes inmersos en el fenómeno de las drogas. Ante esta demanda imperiosa, la Salud Internacional representa una alternativa para analizar y abordar el fenómeno de las drogas y otros problemas de salud de la sociedad nacional y mundial (Alonso, 2003), desde un modelo critico holístico que concibe la salud y la enfermedad como productos sociales y de poder cuyas repercusiones directas recaen sobre el individuo, la familia y la sociedad. Toda esta problemática está determinada por factores macros y micros (Wright, Kirniewicz; Godue; Manfredi,1998) que deben ser analizados para la comprensión total de los problemas en salud que aquejan a la población mundial.

Los microdeterminates, desde la perspectiva de la Salud Internacional, son todos aquellos factores económicos, políticos, tecnológicos, militares, sociales, culturales, familiares e individuales que se encuentran, se interrelacionan y se colocan como trasfondo de las causas que afectan positiva o negativamente las condiciones de la sociedad actual y que a su vez inciden directa o indirectamente en el comercio, producción o consumo de drogas lícitas o ilícitas a nivel nacional. Los macrodeterminantes, por su parte, abarcan todos los anteriores pero en relación con el entorno global, tomando en cuenta la globalización, y las relaciones internacionales.

Esta nueva perspectiva de Salud Internacional ofrece una oportunidad para que los profesionales en Enfermería se involucren -más ampliamente y de forma integral- en la solución de los problema generados, tanto nacional como mundialmente, por el consumo de drogas. Tal como lo menciona Wright (2002), en su propuesta del papel de enfermería y el fenómeno de drogas y la violencia, una de las prioridades de las relaciones internacionales es reducir el abuso de drogas y la violencia y en tal labor la Enfermería debe ser líder en cuanto a la 
disminución de la demanda de drogas y en la producción de conocimiento científico y técnico para tal fin.

Una vez mencionado lo anterior surgen las siguientes interrogantes ¿Porqué la Enfermería puede involucrarse en el abordaje del fenómeno de las drogas? y ¿Porqué la Enfermería puede trabajar desde el enfoque de la Salud Internacional?, Ambas preguntas encuentran una respuesta en la Teoría de Consecución de Metas en Enfermería, desarrollada por King (1984), y en la propuesta teórica de Wright (2002) denominada Modelo Critico Holístico de la Salud Internacional; la primera vertiente define la salud como parte de un constructo social que implica un ajuste continuo a los elementos estresores en el entorno interior y exterior, por su parte, Wright la define como parte de un proceso dinámico de integración en el que intervienen factores de poder e intereses en los niveles nacional e internacional, por tanto, ambas conciben al ser humano como sistemas abiertos que interactúan con el ambiente y, por esa misma razón, los factores externos van a favorecer el que los/as jóvenes se involucren o no con el fenómeno de las drogas.

El sistema de interacción dinámica del individuo, planteado por King (1984), incluye aspectos como la percepción, la imagen corporal, el yo, el crecimiento y desarrollo los cuales se ven influenciados por factores externos como el establecimiento de roles con los demás, las interacciones, transacciones, la comunicación que se ejerza $\mathrm{y}$, a un nivel más macro, se verá influenciado por la familia, el grupo de pares, el trabajo, la religión y la comunidad. Lo mencionado concuerda con lo expuesto por Wright (1999) respecto del modelo crítico- holístico de la salud internacional, en el que se destacan los elementos antes mencionados por King y se añaden otros elementos como los monetarios, los judiciales, internacionales y sus relaciones de poder e intereses, el diseño de políticas y otros que, de manera conjunta, afectan al individuo en cuanto a su situación dentro del fenómeno de drogas ya que cada persona es susceptible a las influencias del entorno.

Por ello, el conocimiento de la Salud Internacional es de gran relevancia pues brinda herramientas para abordar integralmente a la persona, la familia, la comunidad y, de esta forma, mejora las estrategias mediante el desarrollo de investigaciones y el establecimiento de propuestas de programas, proyectos $\mathrm{y}$ políticas que contribuyan a controlar la problemática de las drogas en la población adolescente.

Una vez explicado todo lo anterior, se plantea el siguiente objetivo para esta investigación: analizar los microdeterminates relacionados con el fenómeno de las drogas en la población adolescente costarricense.

\section{Materiales y métodos.}

La investigación responde a un enfoque cuantitativo ya que se fundamenta en los aspectos observables que pueden ser cuantificados o medidos; se utilizó la metodología empírico-analítica utilizada para explicar los fenómenos que ocurren, los factores que los desencadenan y las consecuencias que los producen además de que posibilitan la predicción de su comportamiento (Curcio, 2002) (Hernández, Fernández, Baptista, 2007). Se planteó un diseño y tipo de investigación no experimental, 
transeccional de tipo descriptivo ya que, como se mencionó, no hay una manipulación deliberada de variables y sólo se observan los fenómenos en su ambiente natural en un momento dado para después analizarlos. Cabe destacar que este artículo es pionero y, por tal razón, su gran valor radica en la descripción que se hace del fenómeno de las drogas desde un enfoque novedoso como es la Salud Internacional y la apertura a nuevas investigaciones en esta área.

En lo que respecta a la población estudiada, estuvo constituida por aquellas personas trabajadoras de instituciones nacionales involucradas con el fenómeno de las drogas y con la adolescencia; dichos individuos fueron llamados informantes claves y se seleccionaron a partir de su conocimiento y experiencia en cuanto al fenómeno de las drogas y su relación con la población adolescente; su participación fue voluntaria, hubo previo consentimiento, se respetó el principio de veracidad y el de beneficencia.

Se eligieron nueve informantes claves, algunos de los cuales participan en más de una organización relevante en la temática. Las instituciones a las que representan son las siguientes:

\begin{tabular}{|c|c|}
\hline $\begin{array}{c}\text { Nombre } \\
\text { informante }\end{array}$ & $\begin{array}{l}\text { Institución que } \\
\text { representa }\end{array}$ \\
\hline $\begin{array}{l}\text { Dra. Giselle } \\
\text { Amador }\end{array}$ & $\begin{array}{lr}\text { Integrante del } & \text { Consejo } \\
\text { Directivo del } & \text { Instituto } \\
\text { Costarricense } & \text { sobre } \\
\text { drogas (ICD) y } & \text { Directora } \\
\text { General del Instituto sobre } \\
\text { Alcoholismo } \\
\text { Farmacodependencia } \\
\text { (IAFA) }\end{array}$ \\
\hline Vera & Nacional \\
\hline
\end{tabular}

\begin{tabular}{|c|c|}
\hline Barahona & $\begin{array}{l}\text { Prevención y Tratamiento } \\
\text { de Consumo de Drogas } \\
\text { (IAFA). } \\
\text { Participa en la Oficina de } \\
\text { Naciones Unidas Contra } \\
\text { la Droga y el Delito y en } \\
\text { la Comisión } \\
\text { Interamericana para el } \\
\text { Control del Abuso de } \\
\text { Drogas. }\end{array}$ \\
\hline $\begin{array}{l}\text { Licda. } \\
\text { Eugenia } \\
\text { Mata }\end{array}$ & $\begin{array}{lr}\text { Directora de } & \text { Proyectos y } \\
\text { miembro del } & \text { Consejo } \\
\text { Directivo del } & \text { Instituto } \\
\text { Costarricense } & \text { sobre } \\
\text { Drogas (ICD) } & \\
\end{array}$ \\
\hline $\begin{array}{l}\text { Lic. Carlos } \\
\text { Garita }\end{array}$ & $\begin{array}{l}\text { Miembro del Programa de } \\
\text { Atención Integral al } \\
\text { Adolescente (PAIA), de la } \\
\text { Caja Costarricense del } \\
\text { Seguro Social (CCSS) }\end{array}$ \\
\hline $\begin{array}{l}\text { Dra. } \\
\text { Alejandrina } \\
\text { Mata }\end{array}$ & $\begin{array}{l}\text { Miembro del Consejo } \\
\text { Directivo del ICD } \\
\text { Viceministra Académica } \\
\text { del Ministerio de } \\
\text { Educación Pública (MEP) }\end{array}$ \\
\hline $\begin{array}{l}\text { Dr. Francisco } \\
\text { Dall'Anesse }\end{array}$ & $\begin{array}{l}\text { Miembro del ICD } \\
\text { Fiscal General de la } \\
\text { República, del Ministerio } \\
\text { Publico. }\end{array}$ \\
\hline $\begin{array}{l}\text { Lic. Gerardo } \\
\text { Láscarez }\end{array}$ & $\begin{array}{ll}\text { Viceministro } & \text { de } \\
\text { Seguridad } & \\
\end{array}$ \\
\hline $\begin{array}{ll}\text { Licda } & \text { Rosa } \\
\text { Solís } & \end{array}$ & $\begin{array}{l}\text { Psicóloga de Hogares } \\
\text { CREA, Organización no } \\
\text { gubernamental. }\end{array}$ \\
\hline $\begin{array}{l}\text { Dr. Alex } \\
\text { Rodríguez }\end{array}$ & $\begin{array}{l}\text { Administrador General de } \\
\text { Autogestores de la Salud } \\
\text { de Coronado u Hogar } \\
\text { Salvando al Alcohólico, } \\
\text { Organización no } \\
\text { Gubernamental }\end{array}$ \\
\hline
\end{tabular}

Para recolectar la información fueron creados dos instrumentos: el primero fue un cuestionario con preguntas cerradas y abiertas aplicado por medio de entrevista personal a informantes claves, éste se 
organizó en cuatro dimensiones: sociocultural, sociodemográfica, socioeconómica y ético legal, estos cuatro aspectos analizados son medulares en los microdeterminantes de la Salud Internacional.

El segundo instrumento es una lista de cotejo que ayudó como un mecanismo para revisar ciertos indicadores prefijados y sirvió como medio para verificar estados de avance o tareas pendientes en la revisión documental.

Para analizar los datos, se trianguló la información recolectada por medio de listas de cotejo, entrevistas y fundamento teórico.

Entre las consideraciones éticas, contempladas en esta investigación, se encuentran la fidelidad de la información brindada. Se respetó, igualmente, el principio de justicia, que asegura que no se debe pedir a las participantes del proceso que renuncien a una cantidad excesiva de tiempo, ni que por su participación surjan inconvenientes injustificados. La presente investigación se apegó totalmente al principio de veracidad tanto con las personas participantes como con los resultados. Finalmente, la participación de cada informante fue voluntaria una vez que se les explicó la naturaleza y finalidad de la investigación.

\section{Resultados.}

La presentación de los resultados se hará según las dimensiones fijadas -con antelación- en el apartado de materiales y métodos.

Se partirá de la subdimensión socioculturales: en ésta se contempla el concepto del fenómeno de las drogas; al respecto, los diferentes representantes de las instituciones coinciden con la visión que plantea Salud Internacional, es decir, como un fenómeno de multicausal y multifacético (Wright, 2000), en el que se destacan factores de índole política, jurídica, monetaria, social, tecnológica y cultural, que convergen en la problemática de la drogadicción en la adolescencia costarricense.

Otros aspectos asociados al concepto del fenómeno de las drogas fueron la pobreza, el desempleo, la marginación e inequidad social, las condiciones de vida inadecuadas debido a ingreso económico bajo, la atención escasa en los servicios de salud y la baja oportunidad de desarrollo.

A lo anterior hay que agregar, según los entrevistados, la falta de organización de las diferentes comunidades para proteger a los jóvenes del tráfico, consumo y venta de drogas así como de la deserción escolar.

En cuanto a la violencia social como fenómeno sociocultural, los entrevistados opinaron que las condiciones de vida inadecuadas, el consumismo, la pérdida de valores, el aumento en la violencia y medios de comunicación, el incremento del consumo y tráfico de drogas ilícitas, sumado al déficit de recursos y el efecto de la globalización, son factores que contribuyen a la violación de derechos a la seguridad, al bienestar, al desarrollo, a la salud y a la educación.

Finalmente, en lo que se refiere a la publicidad, todos los informantes refirieron que ésta favorece el consumo de drogas en las personas adolescentes. Además consideran que el IAFA debe 
encargarse de regular esta publicidad negativa.

\section{En la subdimensión sociodemográfica se} contempló -como un elemento fundamental- la familia: las personas encuestadas opinaron que hay familias que consideran que la labor de forjar metas y valores, al igual que la motivación de superación personal, recae en el sistema educativo con el agravante de que muchas familias viven situaciones como desintegración familiar, conflictos de pareja, ausencia de figuras de autoridad y la limitada participación de los padres en la formación de los hijos o hijas.

Asimismo, agregan algunos factores de riesgo individual -en la persona adolescente- tales como: la falta de formación espiritual, una imagen negativa de sí mismo, baja autoestima, falta de asertividad y resiliencia, comportamientos inadecuados como la timidez o la rebeldía, la impulsividad, dificultades para tomar decisiones, carencia de metas y proyectos de vida; los anteriores factores pueden desencadenar conductas peligrosas que favorecen el consumo de drogas.

Respecto de las fuentes de donde fueron tomados los datos sociodemográficos para la programación de los proyectos en las instituciones, las personas entrevistadas afirman que utilizan -principalmenteinvestigaciones propias, datos provenientes de la C.C.S.S, del INEC (Instituto Nacional de Estadística y Censo) y otros documentos como los Informes del Estado de la Niñez y Adolescencia y los brindado por el Consejo de la Persona Joven. Entre los datos más utilizados por estas fuentes están: la población total de adolescentes, la escolarización, la distribución por género y la distribución por zona rural y urbana.

En la subdimensión socioeconómica, un aspecto importante se refiere al tráfico de drogas: los/as entrevistados/as coinciden en que -en los últimos años- se ha dado un aumento del consumo de drogas ilícitas. Algunas razones por las que se da esta situación son: Costa Rica es un lugar de paso para el tráfico de drogas, por tanto, una cantidad importante de droga queda disponible para el consumo interno debido a que muchos costarricenses participan de tal actividad y la misma droga es lo que reciben como paga por sus servicios.

En el área de reducción de oferta y demanda de drogas a nivel nacional, se encontró desconocimiento por parte de los entrevistados, de las funciones, estrategias y relaciones entre instituciones, sumado a una falta de apoyo entre las mismas.

Por último, y relacionado con esta subdimensión, las personas consultadas concluyeron que el mercado capitalista tiene una gran influencia debido a que trae consecuencias como la inequitativa distribución de la riqueza, el aumento en la marginación, el subdesarrollo, el desempleo, la explotación, la migración y la pobreza.

Finalmente, en la subdimensión ético legal, específicamente en las leyes existentes para el control de la oferta y demanda, explicitadas en el Plan Nacional de Drogas (ICD-2007), se encontró que la gran mayoría favorecen el control de la oferta pese a que la demanda tiene igual importancia, además de que las leyes para el control de la oferta continúan siendo ineficaces.

Costa Rica cuenta con convenios y tratados muy importantes en materia de 
drogas con la comunidad internacional, sin embargo, a pesar de que los/as informantes los consideran fundamentales, la mayoría desconoce los procesos internacionales que conlleva y su relación con los demás factores.

Por último, los/as informantes no tienen en su mayoría- un modelo de intervención definido para atender -desde la institución en la que laboran-el fenómeno de las drogas.

\section{Discusión.}

A partir de los datos brindados anteriormente se procede a mostrar el análisis y discusión de los resultados.

La problemática del consumo de las drogas debe ocupar un lugar sobresaliente en la agenda nacional ya que esta situación afecta todo el territorio, igualmente, todos los actores deben involucrarse para poder encontrar estrategias efectivas y apoyo interinstitucional ya que se así se definirán las pautas desde las cuales será abordada la temática relacionada con la prevención, tratamiento y regulación de las drogas. Los encuestados coinciden en que el fenómeno de las drogas no es unicausal sino multicausal, lo cual sirve de base para comprender que el fenómeno de la drogas requiere la intervención de instituciones tanto públicas como privadas.

Como lo apunta la Dra. Amador, "las drogas componen, en toda su dimensión, un fenómeno que trasciende más allá del entorno nacional o personal pues involucran una serie de factores, causas o elementos que trascienden los límites y fronteras de un país o región lo cual evidencia, más que un problema del individuo, problemas de los sistemas políticos, económico y social"; lo anterior coincide con lo expuesto por Wright (2000) quien explica que las drogas deben ser concebidas desde un enfoque multicausal y multifacético, por lo tanto, para comprender tal situación, deben tomarse en cuenta todos los factores que determinan su consumo tanto en el nivel macro como en el micro.

Un aspecto destacado por las personas entrevistadas es el factor social- cultural el cual involucra aspectos como la pobreza, el desempleo, la marginación e inequidad social. Lo mencionado puede verse reflejado en la violencia social tal como lo menciona el representante del PAIA (Programa de Atención Integral del Adolescente, C.C.S.S.) cuando una persona es adicta "busca las maneras de conseguirla (droga), sin importar el medio".

Además, las deficientes condiciones caracterizadas por bajo ingreso económico, mala atención en los servicios de salud y la baja oportunidad de desarrollo, pueden hacer que se elija la opción de venta de drogas. Como lo menciona el Dr. Dall'Anesse, el traficar drogas en una escala menor permite la adquisición de dinero más fácilmente e implica el riesgo de que se conviertan en potenciales consumidores que ven en las drogas una forma de escapar del difícil medio en el que están inmersos caracterizado por la falta de alimentos y vivienda, alto estrés, depresión e insatisfacción personal entre otros aspectos.

Otro factor que aumenta el riesgo de consumo problemático de drogas es la disposición social al consumo de las mismas ya que -como apunta la Dra. Amador- son "los valores sociales que promueven el consumo", dentro de estos 
la llamada "cultura del guaro", donde se considera normal el fumar y tomar licor en la mayoría de las festividades, formando parte de la identidad costarricense (Bejarano, Ugalde y Fonseca, 2004). Esta característica influye fuertemente durante la socialización primaria en la que se incorpora el consumo de drogas lícitas como algo normal (Leiva, Madríz, 2001).

Asociado a lo anterior, los/as entrevistados/as afirman que las relaciones-durante la adolescencia- y la interacción con grupos de pares que consumen drogas ejerce gran influencia en los/as adolescentes lo cual no debe pasarse por alto ya que en este período los grupos de iguales se convierten en el referente para el modelaje de conductas socialmente aceptadas dentro de los grupos (como sería en este caso el consumo de drogas). Esta problemática se ve agravada por la falta de espacios y actividades de esparcimiento

De la misma forma, la deserción escolar representa un factor de que puede aumentar la probabilidad de consumir drogas dado que limita el desarrollo de oportunidades en un mediano plazo puesto que obstaculiza la obtención de un empleo, la independencia económica y la capacidad adquisitiva. No hay que olvidar que las personas adolescentes que desertan de los colegios quedan excluidas de los programas preventivos sobre el consumo de drogas lícitas e ilícitas (Prevención de Riesgo de las drogas y la prevención indicada para aquellos que iniciaron el uso de drogas, pero que no son drogadictos) (IAFA), los cuales se desarrollan dentro de los centros educativos; también son excluidos de la enseñanza de valores (Promoción del Desarrollo de Habilidades para la vida)
(IAFA, MEP): ambos programas funcionan como factores protectores dirigidos a esta población. Por lo tanto, como la menciona la Dra. Barahona y la Dra. Mata, la permanencia de la persona adolescente en el colegio puede ser un factor de protección (por todo lo antes mencionado) o un factor de riesgo dado que hay instituciones educativas en las que existen estudiantes y profesores que consumen y/o trafican drogas dentro de la institución lo cual, a su vez, provoca la incidencia en el consumo.

El ambiente familiar es considerado como el espacio donde el/la joven inicia el aprendizaje de las pautas para vivir en sociedad $y$ se va desarrollando la caracterización de su personalidad. Así lo considera la Dra. Mata Segreda al afirmar que "el aprendizaje inicia en casa y su refuerzo en el resto de ambientes"; asimismo, el fiscal de la República Dr. Dall'Anesse y el Dr. Rodríguez coinciden al mencionar que en el seno de la familia se deben fomentar actitudes positivas en la persona a medida que va creciendo puesto que, de lo contrario, se presentarán aspectos negativos como el decrecimiento de valores culturales, el conformismo y el poco interés de la persona para educarse. Por otra parte, la situación puede verse agravada porque los padres consideran que la formación de sus hijos es una tarea del sistema educativo.

En relación con el entorno familiar, los/as entrevistados/as mencionan los siguientes aspectos como factores de riesgo para el uso y abuso de sustancias adictivas en los/as jóvenes: la desintegración familiar, los conflictos de pareja, la ausencia de figuras de autoridad, la limitada participación de los padres en la formación de los hijos o hijas, el manejo inadecuado de la disciplina, la sobreprotección (permisividad o 
autoritarismo), la falta de comunicación, el consumo de tabaco, alcohol u otras drogas ilícitas por parte de miembros de la familia así como las formas de castigo violento.

Los/as adolescentes no sólo pertenecen a una estructura familiar y social dado que, ante todos, son individuos con características específicas; cada individuo posee, de igual manera, factores de riesgo como: la falta de formación espiritual, una imagen negativa de sí mismo/a, la baja autoestima, la falta de asertividad y resiliencia, los comportamientos inadecuados como la timidez o la rebeldía, la impulsividad, las dificultades para la toma de decisiones, la carencia de metas y proyectos de vida los cuales, según la Dra. Mata Segreda, "son reflejo de múltiples agentes externos que calan en el interior de la persona, además de características propias de la etapa de la adolescencia". Por las razones mencionadas es que debe formarse a la persona desde edades tempranas y debe crearse una cultura de conciencia en la que la sinceridad consigo mismo permita reconocer que se tiene un problema y se logren detectar las fortalezas internas propias que pueden contribuir a resolver las dificultades enfrentadas a través de la vida.

Se puede agregar además el componente comunitario que, como lo menciona Smith (1997), ante la problemática del consumo de drogas es de suma importancia conocer los elementos negativos que se presentan en ese ámbito debido a que éstos tienen gran influencia en el individuo y su formación. Por lo anterior, es que se afirma que el adolescente es moldeado, en gran medida, por las condiciones en las que se ve envuelto. Un aspecto destacado por las personas entrevistadas es la falta de organización comunal para fiscalizar y supervisar el cumplimiento de las leyes, por ende, debe haber planificación y una vigilancia continua dentro de la misma.

A pesar de que los/as entrevistados/as concuerdan en que estos múltiples factores deben ser integrados en el momento de abordar el fenómeno de las drogas, no hay un reflejo de tal iniciativa en las intervenciones porque las actividades institucionales, para controlar la oferta y la demanda, no toman en cuenta todos estos aspectos sino que sus intervenciones son fragmentadas y con una visión localista enfocada en el individuo.

En cuanto a las estadísticas sociodemográficas, son de gran importancia ya que los datos que arrojan brindan la oportunidad de caracterizar la población en estudio y, de esta manera, adecuar la atención brindada. Para el año 2005 ( V Informe del estado de la niñez y la adolescencia en Costa Rica (EDNA), señala que, de la población adolescente, un $50.9 \%$ está conformado por hombres y un $49.1 \%$ por mujeres, por ende, puede concluirse que este grupo poblacional no presenta diferencias numéricas marcadas por sexo.

En cuanto a la escolaridad en el grupo general de adolescentes del país, el VI EDNA (2008) señala que la cobertura en secundaria no sobrepasó el 60\%. Estas cifras muestran una baja escolarización, ya que un $40 \%$ de adolescentes no está incorporado en la educación secundaria. Los datos correspondientes a la permanencia de los/as adolescente en las aulas, en cuanto al área geográfica, arrojan las siguientes observaciones: en las zonas urbanas, la permanencia en los centros educativos es más alta en contraste con la zona rural. En la zona rural, los 
adolescentes tienen menor posibilidad de ingresar a los centros educativos. Asimismo, se concluye que las mujeres, en relación con los varones, tienen menor índice de permanencia dentro de las aulas. Esta deserción escolar traerá importante repercusiones sociales y monetarias debido a que a estas jóvenes les será muy difícil encontrar un buen empleo además de que están en desventaja respecto de aquellas que sí permanecieron en los centros educativos $y$ finalizaron sus estudios.

Los datos más utilizados en sus respectivas instituciones, según las personas entrevistadas, son las cifras relacionadas con la población total de adolescentes seguida de la relacionada con la escolarización, la distribución por género y la distribución por zona rural y urbana. Tales datos son importantes debido a que involucran aspectos determinantes para el abordaje del fenómeno de las drogas por ejemplo: al conocer las cifras de la totalidad de adolescentes es posible determinar la tasa de crecimiento de este grupo y, de esta manera, conocer la importancia y/ o influencia social ejercida por esta población, además, se pueden aunar los esfuerzos necesarios para brindarles la atención requerida en todos los campos.

Cabe mencionar que los representantes de las O.N.G, mencionan que no utilizan ningún dato socio demográfico pese a hacen una división por género para los programas que desarrollan lo hacen; por otro lado, no utilizan la distribución por provincias, contrariamente a lo esperado, ya que el conocer los datos sociodemográficos podría favorecer la asociación de índices de consumo de drogas a elementos como la violencia, la inseguridad, la prostitución, etc.
Respecto de las fuentes o sitios de donde provienen los datos sociodemográficos, los/as entrevistados utilizan principalmente investigaciones propias o provenientes de la C.C.S.S o del INEC (Instituto Nacional de Estadística y Censo); igualmente, usan los Informes del Estado de la Niñez y Adolescencia y del Consejo de la persona joven. Las investigaciones realizadas en la población mencionada son efectivas debido a que se realizan cada 3 años, en cambio, las del INEC se llevan a cabo cada 10 años, las de la C.C.S.S. son bastante sesgadas dado que los jóvenes no frecuentan mucho los centros de salud, además, no utilizan los datos del MEP y del PANI pese a que arrojan información importante en cuanto a factores de riesgo en los centros educativos $y$ de grupos juveniles no incluidos en el sistema educativo. De lo anterior se concluye el sistema de salud debe aumentar la captación de jóvenes, fomentar la investigación y crear un banco de datos confiable y accesible.

Los datos estadísticos más recientes, asociados al consumo de drogas en la población general de jóvenes, se dan entre los años 1990 y el 2007 y provienen principalmente del IAFA el cual puede considerarse el órgano nacional con mayor intervención y competencia en este aspecto; también cuenta con el apoyo de las otras organizaciones como el PANI (Patronato Nacional de la Infancia), el MEP y la CCSS. Las investigaciones que arrojan la gran mayoría de datos se realizan en los centros educativos debido a que albergan gran parte de la población adolescente, por tanto, el acceso a esta población es mucho más fácil en comparación con aquéllos que no están dentro de las instituciones educativas. Según la Dra. Amador, el MEP arroja 
datos muy valiosos acerca de la población escolarizada, por ejemplo, las tasas de deserción escolar, los índices de violencia dentro del sistema educativo y otros aspectos relacionados con la conducta de consumo y /o comercio de drogas dentro de las instituciones educativas.

Por otro lado, el IAFA y otras instituciones como el ICD hacen uso de la información proveniente del PANI para conocer la realidad sobre los/as jóvenes que viven en las calles y en situaciones de extrema pobreza y que, además, están excluidos del sistema educativo. Asimismo, el Ministerio de Justicia para Jóvenes se encarga de los/as adolescentes consumidores de drogas que infringen la ley.

Según el IAFA (2007), las principales drogas consumidas por la población adolescente son el alcohol, el tabaco, y los tranquilizantes; no obstante, esta situación no se limita a la población adolescente sino que se repite en el resto de ciudadanos/as del país. Lo anterior, evidencia que la legalidad del tabaco y el alcohol es un factor determinante para el consumo y aumenta la posibilidad de iniciar el consumo de otras sustancias. De la misma manera, el consumo de tranquilizantes y estimulantes se ve favorecidos por su amplia disponibilidad en farmacias, locales comerciales o en el mismo hogar. Este último constituye el principal espacio donde los jóvenes obtienen esta droga (IAFA, 2006).

Como se mencionó, tanto en la población adolescente como en la población general del país, el alcohol constituye la droga más consumida según la mayoría de las investigaciones: (Bejarano, Amador y Vargas 1994); (IAFA 2000); (Bejarano y Ugalde 2003); (Bejarano, Ugalde, y
Fonseca, 2004); (IAFA 2006); (Folguera, Corral y Gallardo 2007). La Dra. Amador aporta un marco explicativo basado en el hecho de que las costumbres costarricenses giran en torno al consumo de dos drogas principales: el alcohol y el tabaco. Esto debido -por una parte- a su legalidad y facilidad para adquirirlas ypor otra- al hecho de que muchas festividades, religiosas y sociales, han estado relacionadas con el consumo de bebidas alcohólicas (desde tiempos precolombinos); al respecto, la Dra. Barahona, afirma que el consumo del alcohol es visto como algo cotidiano pues la población costarricense no le da mayor importancia al consumo de alcohol lo cual evidencia que su consumo está fuertemente arraigado en la sociedad, de ahí la dificultad para corregir los patrones de consumo y la necesidad de plantear medidas muy bien elaboradas para alcanzar dicho objetivo.

Aunado a lo anterior, la Dra. Amador agrega que la ingesta de alcohol está muy relacionada con el uso de tabaco dado que "la persona o el adolescente asocia el consumo de alcohol y complementariamente fumarse un cigarrillo". Por ende, el alcohol y el tabaco han sido consideradas -por añosdrogas de inicio ya que constituyen el paso a la vida adulta, del mismo modo, la influencia ejercida por los/as amigos/as fomenta el consumo dentro de los grupos de iguales. El tener un/a amigo/a que consuma, la necesidad de pertenecer a un grupo o el querer aumentar la popularidad hace de la población adolescente un blanco bastante vulnerable de desarrollar conductas de consumo de tabaco y alcohol (Nuño; Álvarez; Madrigal y Rasmussen, 2004). 
Si bien es cierto. según el análisis de las investigaciones del IAFA en la década de los 90, se observa un aumento en la prevalencia de consumo de drogas lícitas (alcohol y el tabaco), por encima de drogas ilícitas (crack y la marihuana), en la década actual, las drogas ilegales han tenido una mayor evolución; según el Dr. Dall'Anesse, este incremento vertiginoso de los últimos años, se debe a un aumento en la oferta de la droga en los mercados producto de la globalización lo cual ha convertido a Costa Rica en un lugar en el que transita gran cantidad de droga de la cual mucha se queda en el país para consumo local.

La publicidad es un elemento que no debe ser obviado en esta investigación. Para efectos de este estudio se entenderá como los medios de venta y servicio de bienes dirigidos a la población adolescente con el fin de motivar el consumo de un grupo definido de drogas; además la publicidad está dentro de la clasificación de factores de riesgo ligado a la organización social debido a que las actitudes y creencias sociales comunicadas en los anuncios publicitarios fomentan un mayor consumo en la población aunque el único fin que se persigue es aumentar las ventas del producto.

Bejarano menciona que en la publicidad se involucran elementos que no tienen que ver con el fumado (sensualidad, belleza, diversión, fortaleza, valores, sentimientos) y la exaltación de situaciones de consumo que van más allá de las drogas (Bejarano, 1995: 77); la Dra. Amador comparte esta opinión al mencionar que "la publicidad utiliza todos los medios psicológicos que estén a su alcance con el fin de vender su producto; en este caso, las empresas tabacaleras y de bebidas alcohólicas utilizan medios para que los jóvenes como su principal prioridad consuman sus productos"; sin embargo, según Single (citado por Bejarano, 1995) "no se puede afirmar categóricamente- que la publicidad aumente el consumo; tampoco se puede afirmar que hay suficiente evidencia para rechazar la idea de que la publicidad afecte el consumo" (Bejarano, 1995: 14).

A pesar de lo mencionado en el párrafo anterior, todas las personas entrevistadas coinciden en que la publicidad favorece el consumo de drogas, así, por ejemplo, la Dra. Barahona menciona que "la publicidad va enfocada a la población menor, la cual es una población sensible a la información estereotipada de lo bueno que es consumir, debido a que proyectan imágenes que favorecen $e$ incitan el consumo en los adolescentes y esas imágenes influyen en gran medida en los jóvenes", esto concuerda con lo expuesto por la Licda. Mata quien aduce que "la publicidad es uno de los factores de riesgo más importantes para que los jóvenes consuman drogas, ya que en los mismos se proyectan todo tipo de imágenes agradables para que los jóvenes se envuelvan en el mundo de las drogas"; el Lic. Láscarez menciona que "todo lo que sean imágenes influyen mucho en los adolescentes ya que ellos no son realmente conscientes de los engaños de la publicidad y se dejan envolver por los mismos". Finalmente, la Dra. Mata menciona que "la publicidad que realizan las grandes empresas influye grandemente en el consumo que se dé en los/as jóvenes ya que lo que observan en los anuncios publicitarios es parte de la construcción social desde la que se forman los adolescentes quienes se desarrollan en un medio bombardeado por estímulos visuales que promueven el 
consumo fomentado por los medios de comunicación".

Según las personas entrevistadas, los factores asociados a la publicidad son:

- Una población de jóvenes visualmente muy receptivos y que no conocen el significado de lo que representan las imágenes que se les proyectan.

- Publicidad asociada a ideales de éxito, diversión, belleza y bienestar.

- Imágenes indirectamente adaptadas a la población joven; según Bejarano (1993), el 28\% de la publicidad televisiva y el $50 \%$ de la radiofónica va dirigida de forma indirecta a los jóvenes.

- Programas y Propagandas relacionadas con actividades como conciertos, fiestas patronales, barras libres en donde se consumen este tipo de sustancias.

- La publicidad que previene el consumo no iguala la que lo promueve.

La mayoría de los entrevistados consideran que el IAFA es la entidad que debería encargarse de regular de la propaganda que promueve el consumo; sólo un pequeño porcentaje cree que a esta institución deben sumársele el Ministerio de Justicia, el Ministerio de Salud, MEP, CCSS, Ministerio de Seguridad y los programas de prevención implementados por varias de las instituciones mencionadas. Sin embargo, desconocen aspectos claves tales como: cómo puede darse dicha regulación; dónde está definido qué es el IAFA; quién regula la publicidad relacionada con alcohol y el tabaco; etc. Concuerdan con que hay poca relación interinstitucional y falta de evaluación de las estrategias implementadas por las diferentes instituciones; igualmente, las leyes son insuficientes, hay falta de recursos y es necesario fortalecer las áreas de promoción y prevención.

Para los/as entrevistados/as el hecho de que Costa Rica se haya convertido en un importante puente para el tránsito de drogas y que, por ende, haya aumentado el consumo de las mismas (además hay que añadir el uso de alucinógenos, anfetaminas, estimulantes /tranquilizantes, déficits en control de oferta / demanda), conduce a un incremento de la delictividad, de la violencia social, de los índices de consumo, de la deserción escolar, de la pobreza, de la inseguridad y de un desequilibrio de la economía y más pobreza, por lo tanto, es necesario acrecentar las oportunidades de desarrollo, fortalecer los ámbitos de prevención y represión, aumentar la investigación y la unión interinstitucional tal y como lo establecen las políticas del ICD (2007) y, por supuesto, destinar más recursos económicos y humanos.

Es necesario atender todos los ámbitos implicados en el fenómeno de las drogas los cuales implican producción, tráfico, comercialización, consumo y lavado de dólares dado que, como lo expone Don Francisco Dall' Anesse, Costa Rica ha pasado de ser el segundo país más seguro de América Latina a ocupar el cuarto lugar: tal dado se corrobora en el Plan Nacional de Prevención de la Violencia y promoción de la Paz Social del 2007 al 2010 (2007) que muestra un aumento de hasta un $700 \%$ en la incidencia de robos, de un $100 \%$ en lo que respecta a agresión, más de un $70 \%$ en cuanto a la violencia y un $50 \%$ en homicidios; por la misma razón, la población se siente cada vez más insegura y cree menos en la labor que se desempeña el país en materia de seguridad, (específicamente el rol de la Fuerza Pública). 
En el área de reducción de oferta $\mathrm{y}$ demanda para el consumo de drogas, es evidente que los/as entrevistados/as desconocen las funciones, estrategias y relaciones entre instituciones lo cual se refleja en déficits de fiscalización y apoyo al desarrollo alternativo. Tal incomunicación entre las partes implicadas origina una visión y abordajes fraccionados.

En cuanto a la mala distribución de recursos se encontró que se destina un $86 \%$ a control de la oferta y sólo un $14 \%$ al control de la demanda pese a que ha sido considerada igual de importante (Pernudi, 2006).

En relación con el aspecto socioeconómico, según las personas entrevistadas, el mercado capitalista tiene una gran influencia en aspectos como la inequitativa distribución de la riqueza, el aumento en la marginación, el subdesarrollo, el desempleo, la explotación, la migración y la pobreza; todos los anteriores elementos se relacionan y aumentan las condiciones de riesgo para que los jóvenes y la población se integren con mayor facilidad al mundo de la droga. En este punto, hay que recalcar que la labor de la Enfermería, en los niveles macro y micro, podría generar grandes revoluciones en el abordaje de las problemáticas.

El factor pobreza, tal y como es expuesto por el Instituto Nacional de Estadística y Censo (INEC 2008), produce exclusión de las personas en los distintos sistemas, dicha exclusión genera condiciones de riesgo para el consumo de drogas asociados a su vez con la migración, la globalización, la familia, la educación y las pocas oportunidades de desarrollo.
De lo anterior se concluye que hay pocas oportunidades de desarrollo alternativo dado que son pocos los programas, becas y ayudas para atender las necesidades de los jóvenes, sin embargo, el Plan Nacional de Desarrollo (2008) plantea que Costa Rica continúa esforzándose por mejorar; por su parte, el ICD intenta fortalecer los programas y proyectos en este sentido pero aún es necesario valorar si las alternativas de desarrollo del Ministerio de Planificación Nacional (MIDEPLAN) están dando resultado; este conjunto de elementos evidencia una mayor necesidad de cooperación y relación interinstitucional.

Finalmente, en el aspecto ético legal, específicamente en cuanto a las leyes existentes para el control de la oferta y demanda, en el Plan Nacional de Drogas (ICD-2007) se aprecia que la gran mayoría de las leyes favorecen el control de la oferta aún cuando la demanda es igualmente importante, del mismo modo, se encontró que las leyes para el control de la oferta continúan siendo ineficaces. Aparte, es imperante más apoyo en los procesos de construcción y de reforma jurídica pues la cooperación interinstitucional es bastante fraccionada.

$\mathrm{Si}$ bien es cierto existen convenios y tratados, muy importantes en materia de drogas, ratificados por Costa Rica y por la comunidad internacional, y que son considerados fundamentales por parte de los/as informantes, la mayoría desconoce los procesos internacionales que conllevan y su relación con los demás factores.

Los/as informantes no tienen, en su mayoría, un modelo de intervención definido para atender -desde la institución a la que pertenecen-el fenómeno de las 
drogas, por tanto, es necesario incorporar elementos de orden individual, familiar, comunal, nacional e internacional asociados a factores sociales, culturales, económicos y políticos como lo plantea el Modelo Crítico Holístico de Salud Internacional (Wright 2000).

Como corolario, se puede plantear que el Profesional de Enfermería, desde el Modelo Crítico Holístico de Salud Internacional, puede efectuar un análisis integral de las diferentes problemáticas que afectan al país y al mundo, identificando factores $y$ relaciones implicadas, fortalezas y debilidades desde las que puede plantear soluciones adecuadas y eficaces para los problemas que aquejan a los/as ciudadanos/as, de forma que funjan como agentes de cambio en cualquiera de los sistemas en que se encuentren laborando. Las razones mencionadas justifican no sólo la apertura en el ámbito laboral sino una mayor valorización de la labor llevada a cabo por el/la Enfermero/a (Wright, 2004).

\section{Conclusiones}

- Los/as informantes concuerdan en que el fenómeno de las drogas es multicausal, sin embargo, el abordaje brindado se hace desde una perspectiva local y enfocada en el individuo.

- $\quad$ En Costa Rica se destina un $86 \%$ del presupuesto para el control de la oferta y un $14 \%$ para el control de la demanda.

- Las instituciones nacionales, relacionadas con la temática del consumo de drogas, no ejercen suficiente apoyo y coordinación interinstitucional.

- La salud internacional promueve una mayor participación de los países en vías de desarrollo en la resolución de los problemas que suelen aquejarlos.

- $\quad$ Es fundamental que la Enfermería utilice los aspectos involucrados en la Salud Internacional para abordar de forma más amplia el fenómeno de las drogas.

\section{Bibliografía}

Alonso, P. (2003). Tendencias de la salud internacional: retos $y$ oportunidades para nuestra sociedad. Rev. Gaceta Sanitaria 17 (3). Extraído el 03 de abril 2008 desde http://www.scielosp.org/scielo.php?script=sci_artt ext\&pid=S021391112003000300001\&lng=es\&nr $\mathrm{m}=\mathrm{iso}$

Bejarano, J. Blanco, H. (1993). Análisis de la publicidad de bebidas alcohólicas. San José: Editorial del Instituto Sobre Alcoholismo y Farmacodependencia. IAFA.

Bejarano, J. Blanco, H. (1995). Tabaco, publicidad y salud. Desafíos en la década de los 90. San José: Editorial del Instituto Sobre Alcoholismo y Farmacodependencia. IAFA.

Bejarano, J. Ugalde, F. y Fonseca, S. (2004). Consumo de drogas en la juventud costarricense: análisis de diez años de investigación. Acta psiquiátrica y psicológica de América Latina. 2004, 50(3):203-217 Buenos Aires.

Bejarano J. y Ugalde F. (2003). Consumo de drogas en Costa Rica, resultados de la encuesta nacional del 2000-2001. San José: IAFA

Bejarano, J. Amador, G. y Vargas, L. (1994). Consumo de drogas y percepciones de riesgo en el estudiante costarricense de $10^{\circ}$ y $11^{\circ}$ años 1993. San José: IAFA, MEP.

Curcio, C. (2002). Investigación cuantitativa. Una perspectiva epistemológica y metodológica. Armenia: Editorial Kinesis.

Consejo Nacional de la Política Pública de la Persona Joven (2008). Primera Encuesta Nacional de Juventud, Costa Rica 2007: 
Principales Resultados. San José: Fondo de Población de las Naciones Unidas, UNFPA.

Smith, K. (1997). Factores protectores y de riesgo en las condiciones de vida de estudiantes de segundo ciclo de la Escuela Balvanero Vargas Molina. Estrategia metodológica para su identificación desde el punto de vista de las y los estudiantes. Tesis de Licenciatura. Escuela de Trabajo Social, Facultad de Ciencias Sociales, Universidad de Costa Rica, San José.

Donas, S. (1998). Marco epidemiológico conceptual de la salud integral del adolescente. Washington, D.C: OPS-OMS.

Folguera, M.; Corral, E. y Gallardo, C. (2007). Estudio sobre consumo de drogas en adolescentes. Centro de Salud de RivasVaciamadrid "La Paz". Extraído el 8 de abril de 2008 desde http://www.chospab.es/ investen/diferido/poster/pdf/18.pdf

Hernández, S., Fernández, C. y Baptista, P. (2007). Metodología de la Investigación. México, D.F.: Editorial McGraw-Hill. Interamericana S.A.

Instituto sobre Alcoholismo y Farmacodependencia (2000). Algunos indicadores relacionados con el consumo de bebidas alcohólicas, tabaco y otras drogas en Costa Rica, 1999. San José: IAFA.

Instituto sobre Alcoholismo y Farmacodependencia (2006). La juventud y las drogas. Encuesta nacional sobre percepciones y consumo en población de educación secundaria. San José: IAFA

Instituto sobre Alcoholismo y Farmacodependencia. (2007). Investigación sobre alcoholismo y farmacodependencia en Costa Rica 2001-2005. San José: IAFA.

Instituto Costarricense sobre Drogas (2007). Situación del Tráfico de Drogas en el Sistema Educativo Costarricense. I.C.D. Gobierno de la República de Costa Rica. Extraído el 05 de agosto del 2008 desde http://www.icd.go.cr/sitio/downloads/uploads/web _icd_pdf/pub_2/pub_2_12.pdf

Instituto Costarricense sobre Drogas.(2007). Plan Nacional sobre Drogas 2008-2012. Ministerio de la Presidencia. Extraído el 10 de diciembre de 2008 desde http://www.icd.go.cr

Instituto Nacional de Estadística y Censos (2008). Encuesta de Hogares de Propósitos Múltiples, Julio 2007. San José: INEC.

King, I. (1984). Enfermería como profesión: filosofía, principios y objetivos. México D. F.: Editorial Limusa S.A

Leiva, V.; Madriz, M. (2001). Percepción de drogas en un grupo de niños y niñas en edad preescolar. Revista de Ciencias Sociales

Pernudi, D. (2006). La política de drogas de Costa Rica: Un análisis de las estrategias de intervención. Tesis de doctorado. Universidad de Costa Rica.

Ministerio de Justicia (2007). Plan Nacional de Prevención de la Violencia y Promoción de la Paz Social, 2007-2010. Ministerio de Justicia, UNICEF, San José, Costa Rica.

Mora, C. (2005). Factores protectores en la prevención de consumo de drogas en adolescentes en riesgo. San José. Tesis de Licenciatura. Universidad de Costa Rica.

Nuño, B.; Álvarez, J.; Madrigal, E. y Rasmussen, B. (2004). Prevalencia y factores asociados al consumo de tabaco en adolescentes en una preparatoria de Guadalajara, Jalisco, México. Revista Salud Mental. Octubre 2005. 5(28): 64-70,

Organización Iberoamericana de Juventud (O.I.J.). (1995). Programa Regional de Acciones para el Desarrollo de la Juventud en América Latina. Encuentro Internacional sobre Salud Adolescente. San José: O.I.J.-Secretaría Ejecutiva.

Organización Panamericana de la Salud (1995). La salud de los adolescentes y los jóvenes en las Américas: Escribiendo el futuro. Washington, D.C.: OPS.

Universidad de Costa Rica, UNICEF (2005) V informe del estado de los derechos de la niñez y la adolescencia en Costa Rica. Costa Rica: Universidad de Costa Rica 
Universidad de Costa Rica, UNICEF (2008) VI informe del estado de los derechos de la niñez y la adolescencia en Costa Rica. Costa Rica: Universidad de Costa Rica

Wright, M. (2002). La contribución de la Enfermería frente al fenómeno de las drogas y la violencia en América Latina: un proceso de construcción. Rev Cienc. Enferm 2002. 8 (2). Extraído el 08 abril de 2008 desde http://www.scielo.cl/scielo.php?pid= S071795532002000200002\&script=sci_arttext

Wright, M.. (1999). Las dimensiones del fenómeno de las drogas y la formación de recursos humanos. Brasil.

Wright, M.; Korniewicz, D.; Godue, C.; Manfredi, M. (1998). Salud internacional: el nuevo desafío para la educación de enfermería. Revista Latinoam. Enfermagem. 1998 6(3): 5-10 Extraído el 08 abril de 2008 desde http://www.scielo.br/scielo.php?pid=S0104$11691998000300002 \&$ script $=$ sci_abstract\&tlng=es

Wright, M. (2000). A Critical-Holistic Paradigm for an Interdependent World. American Behavior Scientist, 43 (5): 808-824.

Wright, M. (2004). Liderazgo internacional en Enfermería relacionada con el fenómeno de las drogas: un estudio de caso de la experiencia de colaboración entre la comisión interamericana para el control del abuso de las drogas (CICAD) y la Universidad de Alberta-Facultad de Enfermería. Rev Latino-Americana Enfermagem 2005 13(número especial). Extraído el 08 de abril de 2008 desde www.eerp.usp.br/rlae. 